\title{
Accumulation of neural activity in the posterior insula encodes the passage of time
}

\author{
Marc Wittmann a,b,c, ${ }^{*}$, Alan N. Simmons ${ }^{a, b}$, Jennifer L. Aron ${ }^{a}$, and Martin P. Paulus ${ }^{a, b}$ \\ aDepartment of Psychiatry, University of California San Diego, 8939 Villa La Jolla Dr. Suite 200, La \\ Jolla CA 92037-0985, USA \\ beterans Affairs San Diego Healthcare System, San Diego, USA \\ cDepartment of Empirical and Analytical Psychophysics, Institute for Frontier Areas of Psychology \\ and Mental Health, Wilhelmstrasse 3a, 79098 Freiburg, Germany
}

\begin{abstract}
A number of studies have examined the perception of time with durations ranging from milliseconds to a few seconds, however the neural basis of these processes are still poorly understood and the neural substrates underlying the perception of multiple-second intervals are unknown. Here we present evidence of neural systems activity in circumscribed areas of the human brain involved in the encoding of intervals with durations of 9 and 18 seconds in a temporal reproduction task using event-related functional magnetic resonance imaging (fMRI). During the encoding there was greater activation in more posterior parts of the medial frontal and insular cortex whereas the reproduction phase involved more anterior parts of these brain structures. Intriguingly, activation curves over time show an accumulating pattern of neural activity, which peaks at the end of the interval within bilateral posterior insula and superior temporal cortex when individuals are presented with 9- and 18-second tone intervals. This is consistent with an accumulator-type activity, which encodes duration in the multiple seconds range. Given the close connection between the dorsal posterior insula and ascending internal body signals, we suggest that the accumulation of physiological changes in body states constitutes our experience of time. This is the first time that an accumulation function in the posterior insula is detected that might be correlated with the encoding of time intervals.
\end{abstract}

\section{Keywords \\ time perception; duration reproduction; insular cortex; fMRI}

\section{Introduction}

The experience of time is fundamental for perception and behavior and, thus, essential for the survival of the organism (Buhusi \& Meck, 2005; Wittmann \& Paulus, 2008). Although studies have pointed to several brain areas involved in the processing of duration, to date conclusive answers to the questions of which areas of the brain and what kind of neurophysiological

\footnotetext{
(c) 2010 Elsevier Ltd. All rights reserved

"Corresponding author: Institute for Frontier Areas of Psychology and Mental Health, Wilhelmstrasse 3a, 79098 Freiburg, Germany. Tel.: +49 7612072173 , Fax: +49 76120721 99, wittmann@igpp.de.

Publisher's Disclaimer: This is a PDF file of an unedited manuscript that has been accepted for publication. As a service to our customers we are providing this early version of the manuscript. The manuscript will undergo copyediting, typesetting, and review of the resulting proof before it is published in its final citable form. Please note that during the production process errors may be discovered which could affect the content, and all legal disclaimers that apply to the journal pertain.
} 
processes account for the experience of time in humans have remained elusive (Wittmann, 2009). Over the past decade, a number of different brain areas have been implicated as key parts of the neural time-keeping mechanism in the milliseconds-to-a-few-seconds time range: notably, the cerebellum (Gooch, Wiener, Wencil, \& Coslett, 2010; Ivry and Spencer, 2004), the right posterior parietal cortex (Bueti, Bahrami, \& Walsh, 2008), the right prefrontal cortex (Lewis \& Miall, 2003a; Smith, Taylor, Lidzba, \& Rubia, 2003), a right fronto-parietal network (Harrington, Haaland, \& Knight, 1998; Rao, Mayer, \& Harrington, 2001), and fronto- (SMA) striatal circuits (Hinton \& Meck, 2004; Jech, Dusek, Wackermann, \& Vymazal, 2005; Koch, Brusa, Oliveri, Stanzione, \& Caltagirone, 2005; Koch, Costa, Brusa, Peppe, Gatto, Torriero, Lo Gerfo, Salerno, Oliveri, Carlesimo, \& Caltagirone, 2008). The involvement of many brain areas in the processing of time is most likely due to the involvement of cognitive processes that are not necessarily related to the encoding of duration, e.g. attention, working memory and decision-making (Livesey, Wall, \& Smith, 2007; Rao at al., 2001). Moreover, different processing stages directly linked to the estimation of time may come into play (Morillon, Kell, \& Giraud, 2009). In addition, this list is expansive as it includes studies on numerous time intervals, which recruit different brain areas. Several studies and meta-analyses have indicated that, for instance, millisecond timing is governed by different processes than time perception in the seconds or multiple-seconds range (Lewis \& Miall, 2003a; Pöppel, 1997; 2009; Wiener, Turkeltaub, \& Coslett, 2010; Wittmann, Carter, Hasler, Cahn, Grimberg, Spring, Hell, \& Vollenweider, 2007).

There is also a lack of consensus as to what mechanisms account for our sense of time. The most prominent cognitive models for the time range of milliseconds to seconds have been variants of a pacemaker-accumulator clock where an oscillator produces a series of pulses and the number of pulses recorded over a given time span represents experienced duration (Church, 1984; Treisman, Faulkner, Naish, \& Brogan, 1990; Zakay \& Block, 1997). Other theoretical models assume specific neuronal system properties for encoding time not related to a pacemaker (Karmarkar \& Buonomano, 2007; Matell \& Meck, 2004; Wackermann \& Ehm, 2006), or propose that memory decay processes are involved in time perception (Staddon, 2005), or postulate that the amount of energy spent during cognitive processing defines the subjective experience of duration (Eagleman \& Pariyadath, 2009).

To date, most neuroimaging studies have employed intervals ranging in duration from milliseconds to just a few seconds. With data acquisition times (repetition time, TR) in typical fMRI studies of around $2 \mathrm{~s}$ it is difficult to disclose how neural activity develops over time, an important indicator for a potential temporal-processing mechanism in an identified brain region (the how and where of time processing in the brain). However, with the comparably longer time intervals we were able to investigate how neural activity related to the perception of duration evolves over time. We aimed at collecting empirical evidence of neurophysiological activity (time activity curves) linked to the encoding and reproduction of 9 and 18 second durations in an interval reproduction task recorded with event-related fMRI.

\section{Materials and methods}

\subsection{Subjects}

14 right-handed subjects ( 7 female/7 male); mean age: 25 (age range: 20 to 32) participated in a temporal reproduction task while undergoing fMRI. All subjects were free of neurological, psychiatric or medical illnesses, as determined by interview for DSM-IV diagnoses with the semi-structured psychiatric interview SSAGA (Bucholz, Cadoret, Cloninger, Dinwiddie, Hesselbrock, Nurnberger Jr, Reich, Schmidt, \& Schuckit, 1994), had normal structural MRI scans, gave written consent and were compensated with $\$ 50$ for participation in the study that lasted approximately 90 minutes. The experimental protocol was approved by the UCSD Human Research Protection Program. 


\subsection{Tasks}

The task design is displayed in Fig. 1. In the temporal reproduction task participants were instructed to reproduce the duration of tones (with intervals of 3,9 , and 18 s) by pressing a key when they believed that a second comparison tone had reached the length of a previously presented tone. Each trial started with a $1.2 \mathrm{kHz}$ tone presented for one of the three durations (the encoding tone), followed by a variable pause with an average of $6 \mathrm{~s}$, after which a $2 \mathrm{kHz}$ tone (reproduction tone) was presented. After the second tone had started, subjects had to switch off the tone by pressing a key when they estimated that the duration of the first tone had elapsed. Subjects were additionally instructed to press a key as quickly as possible after the first tone had ended (reaction time). Pause durations were jittered by using values from a set of durations retrieved from an exponential function with a mean value of $6 \mathrm{~s}$. To reduce the possibility of counting, subjects were required to do a secondary memory task in addition to being instructed not to use methods such as counting or tapping to complete the task. Just before the presentation of the tone, four numbers between zero and nine were presented simultaneously for $3 \mathrm{~s}$. The subjects were requested to memorize these numbers. After the second tone had been switched off by the subject one number appeared and the subjects had to respond within $3 \mathrm{~s}$ whether the presented number was one of the four presented at the beginning by pressing one of two buttons (left button for 'yes', right button for 'no'). It is crucial to control for counting strategies with which subjects keep track of time during time estimation tasks. Chronometric counting leads to substantially more precise estimates than pure time estimation and is also guided by different brain structures (Hinton, Harrington, Binder, Durgerian, \& Rao, 2004). Volunteers repeatedly report that the tendency to count or use other strategies of subdividing the presented time interval is rather strong. To prevent participants from using such strategies we presented them with the secondary memory task. We specifically designed this secondary task to have subjects memorize numbers. The task should interfere with counting because both require processing in the same modality. The inter-trial interval was adjusted to the subjects' response times in order to have identical run durations for each subject (11 min. $55 \mathrm{~s}$ ). The maximum duration of the reproduction tone was $150 \%$ of the duration of the encoding tone. An extra inter-trial duration with a time jitter retrieved from an exponential function with a mean duration of 1.5 sec. was added to avoid having the inter-trial interval dependent on the subject's timing.

In the reaction time control task subjects were instructed to listen to $2 \mathrm{kHz}$ tones with durations of around $3 \mathrm{~s}, 9 \mathrm{~s}$, and $18 \mathrm{~s}$ (control duration) and to press the button as quickly as possible as soon as the tone stopped. Unbeknownst to the subject, the tone durations were identical to the reproduced durations in the reproduction task of a previous behavioral session outside the scanner. This procedure was inspired by the method used by Hinton and Meck (2004). In order to have identical run times across all subjects ( $8 \mathrm{~min} .44 \mathrm{~s}$ ), and similar to the temporal reproduction task, the inter-trial interval was adjusted by subtracting the individually performed reaction time to the tone and the decision time in the memory task from a constant and adding a jittered duration of around $1.5 \mathrm{~s}$ (duration retrieved from an exponential function). Each participant was instructed to respond as quickly as possible to the end of the tone to equate for attention and motor preparation demands of the time reproduction task, both in the encoding and the reproduction phase. The control task was embedded in the identical secondary memory task as presented in the timing task.

\subsection{Experimental procedure}

Each subject was trained in the two tasks (temporal reproduction, control reaction time) outside the scanner before the imaging session. Specifically, a behavioral version of the temporal reproduction task was presented in order to gain stimulus durations for the control task in the scanner. Subjects were instructed not to count during the task. It was stressed that the investigator was not interested in the subjects' counting abilities, but in the subjective estimates of duration. Nevertheless, to further prevent counting, the secondary memory task was 
employed. Stimulus presentation and response registration were controlled using a program created with the WinVis toolbox (Neurometrics Institute) for MATLAB (Version 5.3, MathWorks Inc.). For imaging acquisition, both the temporal reproduction and the control task were presented twice in alternating order. Half of the 14 subjects received the presentation order $\mathrm{ABAB}$ and the other half the order BABA. A run in each task (reproduction, control) contained six presentations of each of the three durations, adding up to 36 duration presentation in each task ( 2 runs $\times 6$ presentations $\times 3$ intervals). The respective time intervals in the time perception and the control tasks were presented in randomized order across the recording session and across subjects.

\section{4. fMRI scanning}

Participants were scanned in a 3T GE Signa scanner using an 8-channel head array coil. Each scanning session consisted of a three-plane scout scan, a sagittally acquired spoiled gradient recalled (SPGR) sequence for acquiring T1-weighted images (FOV $25 \mathrm{~cm}$; matrix: 192×256; 172 slices; thickness: $1 \mathrm{~mm}$; TR: $8 \mathrm{~ms}$; TE: $3 \mathrm{~ms}$; flip angle: $12^{\circ}$ ) and four T2*-weighted axially acquired echo-planar imaging (EPI) scans to measure blood oxygen level dependent (BOLD) signals. The parameters for the EPI scans were $3.43 \times 3.43 \times 2.6 \mathrm{~mm}$ with a $1.4 \mathrm{~mm}$ gap, TR=2 seconds, TE $=32 \mathrm{~ms}$, flip angle of 90 degrees, and 30 slices (whole brain). Cushions were arranged around the head and neck to maximize comfort and minimize motion.

\subsection{Image processing and analysis}

The data were preprocessed, normalized to Talairach coordinates (Talairach \& Tournoux, 1988) and analyzed with the Analysis of Functional NeuroImages (AFNI) software package (Cox, 1996). For preprocessing, voxel time series data were interpolated to correct for nonsimultaneous slice acquisition within each volume and corrected for three-dimensional motion. Motion-corrected voxel time series data were visually inspected to remove large movement artifacts. Preprocessed time series data for each individual were analyzed using a multiple regression model containing 15 regressors. Specifically, nine response regressors were generated for each of the three durations (3-, 9-, 18-s) for (1) the encoding phase and (2) the reproduction phase of the temporal reproduction task, as well as for the (3) control duration in the control task. Three regressors were generated across a given run in order to model residual motion (in the roll, pitch, and yaw directions). A further regressor generated across the individual runs was included for filtering out activation attributable to noise. To do this white matter was segmented and the time series was extracted and entered as a regressor to the deconvolution analysis. In addition, baseline and linear regressors were included in the regression model. Each of the nine behavioral regressors was convolved with a modified gamma variate function modeling a prototypical hemodynamic response. The magnitude of the regressors of interest were scaled to the shortest duration regressor ( 3 seconds) to assure that the resulting estimation of the beta coefficient were comparable across conditions. Subsequently, regressor coefficients are normalized with respect to the baseline coefficient to obtain \% signal change measure. The scaling across the regressors of interest is necessary to be able to directly compare their relative $\%$ signal change. In addition, The AFNI program $3 \mathrm{dDeconvolve}$ (Cox, 1996) was used to calculate the estimated voxel-wise response amplitude and function for each regressor and to generate three contrasts for each of the three duration conditions: encoding phase versus control phase, reproduction phase versus control phase, reproduction phase versus encoding phase. A Gaussian filter with full-width half-maximum (FWHM) of $6 \mathrm{~mm}$ was applied to the voxel-wise percent signal change data to account for individual variations of the anatomical landmarks. Data from each subject were normalized to Talairach coordinates. Following two-way repeated measure ANOVAs to test for activation differences in the three contrasts (encoding phase versus control phase, reproduction versus control phase, reproduction phase versus encoding phase) over the three interval durations, voxel-wise one-sample t tests were used to identify brain areas in which the signal data differed 
significantly between the contrasted conditions for each of the three intervals (3-, 9-, 18-s). Activations are coded by yellow to red voxels (activation) and blue (deactivation) and superimposed on the average of anatomical images of the 14 subjects. A threshold adjustment method based on Monte-Carlo simulations was used in a whole-brain cluster analysis. Based on these simulations, it was determined that a voxel-wise a-priori probability of 0.01 would result in a corrected cluster-wise activation probability of 0.01 and a voxel-wise a-posteriori probability of 0.00000496 if a minimum volume of $704 \mu \mathrm{l}$ and a connectivity radius of $4.0 \mathrm{~mm}$ (corresponding to 11 connected voxels) was considered.

Areas of significant activation as found for the indicated contrasts (encoding phase versus control task, reproduction phase versus control task) were defined as ROI for plotting the time activity curves across the time intervals of interest $(9 \mathrm{~s}$ and $18 \mathrm{~s}$ in the encoding and the reproduction phase). Time activity curves for the encoding phase: in order to compare the individual BOLD signal at each time point across subjects, time activity was set to zero at the onset of the stimulus. Subsequent values per individual represent the difference between the time point $\mathrm{t}_{1}, \mathrm{t}_{2}$, etc. and $\mathrm{t}_{0}$, respectively. Time activity curves for the reproduction phase: individual time activity curves for the 9- and 18-s reproduction phases were aligned to the actual individual reproduction times of the participants (stopping the tone in the reproduction phase plus the projected delay of the hemodynamic function). Time activity curves are plotted in intervals of $2 \mathrm{~s}$ which corresponds to the acquisition time of brain activation in the scanner (TR). Time activity curves are not shown for the $3 \mathrm{~s}$ interval due to the fact that they comprise only one acquisition. It is important to note that although the ROI depend on the selected contrasts (and thus on the difference of activation between the timing phases and the control task phase) the time activity curves themselves are independent of the control task and only represent neural activation during the encoding and the reproduction phase.

\section{Results}

\subsection{Behavioral}

In accordance with former studies employing the temporal reproduction method (Eisler \& Eisler, 1992; Noulhiane, Pouthas, \& Samson, 2009; Sawyer, Meyers, \& Huser, 1994; Ulbrich, Churan, Fink, Wittmann, 2007; Vierordt, 1868), the mean of the reproduced intervals were accurate for the $3 \mathrm{~s}$ interval (mean reproduction: $2.918 \mathrm{~s}$; S.D.: 0.628) but with increasing interval lengths were progressively under-reproduced relative to physical time: 7.576 s (S.D. $=1.434$ ) for the 9-s interval and $12.702 \mathrm{~s}($ S.D. $=2.723)$ for the 18-s interval (see Supplementary Content Fig. 1). Correlations among the lengths of the three reproduction intervals (as performance index) reveal that only the 9-s and 18-s reproduction intervals, but not the 3-s, were significantly correlated $(r=0.827 ; \mathrm{p}<0.0001$, two sided $)$.

\subsection{Imaging}

First, we examined which brain areas are activated during the encoding and reproduction phase for the three different durations. Two-way (fixed factor: duration, random factor: subject) analyses of variance (ANOVA) were conducted to test the differences of activation for the three contrasts: (1) encoding versus control phase, (2) reproduction versus control phase, and (3) reproduction versus encoding phase ( $p<0.01$, corrected). Several brain areas were significantly activated for the contrast effects shown separately for the three durations (Tables $1,2,3)$. Specifically, the supplementary motor area (SMA) was activated across all durations in the encoding phase. Particularly for the 9- and 18-s intervals, activations in posterior insular and superior temporal cortices were found. Relative to the encoding phase, the reproduction of time intervals engaged more anterior portions of the brain, which is most evident in the anterior shift of medial frontal (SMA to pre-SMA) activation during the 9- and 18-s intervals (compare Fig. 2 with Fig. 3). This posterior-to-anterior shift was also observed in the insula. 
In the encoding phase only posterior structures of the insular cortex showed significant activation differences (Fig. 2); whereas anterior insula activation was observed in the reproduction phase activation, which was more pronounced than posterior insular activation (Fig. 3). The contrast reproduction phase versus encoding phase complements these findings of a posterior-to-anterior shift (two-way ANOVA; $\mathrm{p}<0.01$, corrected, Table 3), showing for the 9- and 18-s intervals that posterior insula is active in the encoding phase (Fig. 4, $\mathrm{z}=12$; activation coded in blue) but that the anterior insula is active in the reproduction phase (for the 9-s interval; Fig. 4, z = 2; activation coded in yellow to red). In addition, activation in medial frontal cortex for the 3-and 9-s intervals shifts from the encoding to the reproduction phase in the anterior direction (Fig. 4, $\mathrm{x}=7$ ). In Table 3 those regions of the contrast between the reproduction and encoding phase are highlighted in bold which are regionally similar to the respective encoding > control and reproduction > control contrasts (from Table 1 and 2). When comparing these contrasts it becomes clear how mainly inferior frontal, anterior insula and SMA are activated in the reproduction phase and posterior insula and SMA are activated in the encoding phase.

To directly assess whether the different interval lengths resulted in different brain activation, we conducted a whole-brain analysis for significant ( $\mathrm{p}<0.01$, corrected) contrasts in three conditions for both encoding versus control and reproduction versus control: ' $3 \mathrm{~s}$ versus $9 \mathrm{~s}$ ', ' $3 \mathrm{~s}$ versus $18 \mathrm{~s}$ ', and ' $9 \mathrm{~s}$ versus $18 \mathrm{~s}$ ' (Supplementary Tables 1, 2). The left sided posterior insula, the superior temporal and inferior parietal gyri was significantly more activated in the $9 \mathrm{~s}$ than the $3 \mathrm{~s}$ encoding interval. In addition, the left and right SMA was significantly more strongly activated in the $18 \mathrm{~s}$ than the $3 \mathrm{~s}$ encoding interval. Finally, right sided superior and middle frontal area was significantly more activated in the $3 \mathrm{~s}$ than in the $18 \mathrm{~s}$ encoding condition. Three ROI were significantly more active during the reproduction phases in the 18 $\mathrm{s}$ than the $3 \mathrm{~s}$ interval condition: (1) the left and right pre-SMA and SMA, (2) the right inferior parietal gyrus, (3) a region encompassing the right post-central and inferior parietal gyri.

\subsection{Time activity curves}

Our second question focused on the time course of neural activity in the identified brain regions of interest (ROI) for the 9- and 18-s intervals. We used the areas of significant activation between the encoding phase and control task as well as the reproduction phase and the control task (Tables 1,2) as ROI for plotting brain activity over time during the phases of interest (the encoding and reproduction intervals). Individual time activity curves during the 9- and 18-s encoding phases were normalized (set to zero for the purpose of inter-individual comparison) at the onset of the stimulus and plotted in intervals of $2 \mathrm{~s}$ (TR). That is, the time activity plots are solely based on the activation over time during the selected phase of the task (encoding, reproduction). We found two fundamentally different temporal activation patterns (Fig. 2): (1) a rapid-onset, steady increase of activation over time or 'climbing activity' that peaks at the end of the stimulus (the assumed peak of the hemodynamic function $=$ stimulus length $+\sim 6$ $\mathrm{s}$ delay) and (2) an inverted $\mathrm{u}$-shape activation that increases with a considerable delay after stimulus onset and decreases before the end of the stimulus. A factor analysis conducted over the time courses of activation in the encoding phase in the ROI of the encoding versus control contrast confirms the existence of two different factors corresponding to the two observable temporal activation patterns (Table 4). In the 9-s condition, climbing activity is detectable in the ROI that encompasses the right-sided posterior insula and portions of the superior temporal and pre-central gyrus (Fig. 2). 13 out of the 14 subjects have a positive linear slope (one-sample t-test: $\left.\mathrm{t}_{1,13}=6.8 ; \mathrm{p}<0.0001\right)$. In the 18-s condition, climbing activity is visible for the ROI in the right posterior insula (and parts of the post-central gyrus) (13/14 subjects have a positive slope; one-sample $\mathrm{t}$-test: $\left.\mathrm{t}_{1,13}=4.1 ; \mathrm{p}<0.001\right)$, the left posterior insula $\left(13 / 14 ; \mathrm{t}_{1,13}=3.6 ; \mathrm{p}\right.$ $<0.003)$, and a right superior temporal and inferior parietal region $\left(14 / 14 ; \mathrm{t}_{1,13}=6.5 ; \mathrm{p}<\right.$ 0.0001) (Fig. 2). 
Inverted u-shape functions in the 9- and 18-s conditions of the encoding phase are seen for the right pre-central gyrus, the SMA bilaterally (Fig. 2) and an area spanning right pre-post central gyri. Focusing on the activity in SMA, a region that has been repeatedly suggested as serving specific timing functions, and inspecting individual time activity curves, 12 out of 14 subjects in the 9-s condition have this $\mathrm{u}$-shape functions with a peak either at 8,10 , or $12 \mathrm{~s}$; in the 18 s condition 10 out of 14 subjects exhibit this inverted u-shape activity with peaks at 8 to $12 \mathrm{~s}$. A ROI encompassing the left posterior insula, parts of the pre-post central gyrus as well as superior temporal gyrus displays characteristics of both types of time activity curves.

Specifically, the activation increases immediately after stimulus onset and plateaus before dropping shortly prior to the end of the stimulus (Fig. 2), which resulted in a positive slope in 11 out of the 14 subjects $\left(\mathrm{t}_{1,13}=3.5 ; \mathrm{p}<0.004\right)$.

In the reproduction phase, time activity in different ROI exhibit a similar temporal profile, i.e. show a monotonic rise followed by a sudden drop at around the button press (Fig. 3). This pattern can be seen during the reproduction of the 9-s intervals for the ROI identified to be located in the right pre-SMA, the right post-central and inferior parietal cortices, the left inferior frontal cortex, the right anterior insula, right inferior frontal cortex, the left posterior insula (Table 2). During the reproduction of the 18-s interval this activation pattern emerges only $\sim 10$ $\mathrm{s}$ before the button press in the ROI in a right medial frontal area, the left anterior insula, and the right anterior insula. Here, the drop of activation already starts around 2 to $4 \mathrm{~s}$ before the button press. It is important to note that although we temporally aligned individual brain activation patterns of the reproduction phase as closely as possible to the time of the button press, due to the temporal resolution of our fMRI recording with a TR of $2 \mathrm{~s}$ we had to shift the activity during performance (say, a reproduced interval of $9.2 \mathrm{~s}$ ) to the prior time point of acquisition (in this case, at $8 \mathrm{~s}$ ). This approach leads to an artificial earlier peak of up to (though on average less than) $2 \mathrm{~s}$.

Finally, we tested whether the brain activation pattern found during the encoding phase was specific to this task phase. Therefore, we inspected time activity curves evolving during the control phase in the identical ROI used for the time activity curves during the encoding phase (Fig. 5). Since the duration of the control interval was defined by the subjects' actual reproduced durations of a previous behavioral session (see 2.3. Experimental Procedure), the average duration of the control task was 7.5 and 12.7 seconds for the 9-s and 18-s encoding intervals, respectively. Individual time activity curves during these two time intervals were set to zero at the onset of the stimulus. For the slope estimates, time activity curves corresponding to the average duration of an individual's control task were taken. Inspection of the 7.5-s control condition reveals no visible rise of activity over time in the left- $(6 / 14$ subjects have a positive linear slope; one-sample t-test: $\left.\mathrm{t}_{1,13}=-1.2 ; \mathrm{p}=0.26\right)$ and right-sided region $\left(5 / 14, \mathrm{t}_{1,13}=-0.46\right.$; $\mathrm{p}=0.65$ ) encompassing the posterior insular and superior temporal cortex (Fig. 5). In the 12.7$\mathrm{s}$ control condition a prominent rise of activity can be seen in the right superior temporal and inferior parietal cortex. The peak of this average activity occurs at a stimulus duration of $\sim 8$ $\mathrm{s}(8 \mathrm{~s}$ stimulus duration plus the projected hemodynamic response latency of ca. $6 \mathrm{~s}$ results in a peak at $14 \mathrm{~s}$ ) partly reflecting the fact that some individual presentation times (corresponding to the temporal reproduction times) were shorter than the average of $12.7 \mathrm{~s} .10$ out of 14 subjects have positively rising activity, but a one-sample t-test shows that the slopes are not significantly different from zero $\left(\mathrm{t}_{1,13}=1.7 ; \mathrm{p}=0.114\right)$. In the left posterior insula, a rise in activity appears only towards the end of the interval and a positive slope is found in 11/14 subjects.

Nevertheless, this rising activity is not significantly different from zero $\left(\mathrm{t}_{1,13}=1.75 ; \mathrm{p}=0.104\right)$ (Fig. 5). To determine whether the slopes detected during the encoding phase are encoding specific, i.e. that they do not occur in the control task, is supported by a paired samples statistics (two-sided t-tests) for the slopes between the encoding phase and the control phase in the identical ROI. For the 9-s condition, compared to the control condition slopes are significantly greater in the encoding condition in the right $\left(\mathrm{t}_{1,13}=4.4 ; \mathrm{p}<0.001\right)$ as well as the left posterior 
insula $\left(\mathrm{t}_{1,13}=2.2 ; \mathrm{p}<0.047\right)$. In the 18 -s condition, compared to the control condition slopes are significantly more pronounced during the encoding of duration in the right posterior insula $\left(t_{1,13}=3.0 ; p<0.011\right]$ and the right superior temporal and inferior parietal region $\left(t_{1,13}=3.2\right.$; $\mathrm{p}<0.007)$ but not the left posterior insular cortex $\left(\mathrm{t}_{1,13}=0.47 ; \mathrm{p}=0.64\right)$. Concerning the SMA activation, no particular activity pattern is visible in the $7.5 \mathrm{~s}$ condition; however, the activation for the 12.7-s control condition shows a similar rise-and-fall pattern as was seen in the encoding phase for the SMA.

\section{Discussion}

This manuscript examined the neural substrates that underlie the processing of time in the seconds domain. In particular, activation was observed in brain regions related to the encoding and reproduction of time intervals which have been implicated as core neural substrates of time-keeping systems, notably the supplementary motor area, the striatum, cerebellum, the right frontal lobe, the inferior parietal gyrus, the posterior temporal cortex as well as the insula (Lewis \& Miall 2003a; b; Rubia \& Smith, 2004; Wiener et al., 2010; Wittmann, 1999). Specifically, the encoding phase activated more posterior regions in the medial frontal (including SMA) and the insular cortex. The reproduction phase (with a strong motor component) involved more anterior aspects of the cortex. From the identification of regions of activity alone, however, one cannot infer whether a particular brain area actually serves as a time-keeping mechanism or whether it is involved in time perception through supportive functions such as attention, working memory, or motor plans. What we show here with time activity curves is a specific neural activation pattern over time in the encoding phase in the posterior insula (encompassing the dorsal posterior insula, the primary interoceptive area), which can be interpreted as encoding time intervals in the multiple-second range. In contrast to the brain activation pattern during the encoding phase, time activity in the reproduction phase in several brain regions such as the anterior insula, the inferior frontal cortex as well as the preSMA, increases steadily and peaks shortly before the motor response. Whereas mounting activity in the encoding phase spans the time range of the whole interval ( 9 and $18 \mathrm{~s}$, respectively), and thus mirrors the duration of the presented tone, mounting activity in the reproduction phase starts approximately $10 \mathrm{~s}$ before the button press for both of these time intervals. In the 9-s reproduction phase the moment of the button press and the decrease in activation coincide much better than in the 18 -s condition. In addition, there is greater variance in recorded activity in the 18-s condition. This may be due to the length of the temporal interval, which is more difficult to represent and to hold in working memory. It seems as if the more posterior regions of the brain are instrumental in coding the duration of a presented interval and that many distributed (more anterior) regions of the brain are involved in keeping a representation of that interval for further processing (pressing the button at the right moment in time).

The time activity curves in the encoding phase are not unlike those recently reported in neurophysiological animal studies showing that climbing neuronal activity, interpretable as representing a temporal integrator-like function, encodes short durations (Durstewitz, 2003; Reutimann, Yakovlev, Fusi, \& Senn, 2004). Neuron ensembles in pre-motor and motor cortex (Lebedev, O'Doherty, \& Nicolelis, 2008) as well as posterior parietal cortex (Leon \& Shadlen, 2003) of rhesus monkeys monotonically increase (or decrease) their activity throughout delays up to a few seconds before a timed motor response is made. Similarly, in humans slow negative waves as measured with EEG over frontal-central areas peak at the end of anticipated durations in the range of milliseconds to a few seconds (Pfeuty, Ragot, \& Pouthas, 2005; Praamstra, Kourtis, Fei Kwok, \& Oostenveld, 2006). Whereas in these EEG studies the source of activity cannot be precisely located, we show climbing activity in circumscribed areas of the brain, namely the posterior insula and the superior temporal gyrus. We interpret this activation as indication of an ensemble accumulator process, i.e. the increasing engagement of multiple local 
neural circuits to encode duration of auditory signals (thus, the engagement of the superior temporal cortex). Theoretical models have been developed showing how signal accumulation over time can function as a time keeper (Reutimann et al., 2004; Wackermann \& Ehm, 2006).

Activation of the insular cortex has repeatedly been shown in neuroimaging studies on time perception but its significance has seldom been discussed (Lewis and Miall, 2003a; b; Livesey et al., 2007; Rao et al., 2001). It is only very recently that a conceptual framework for an anatomical and structural model involving the insular cortex in time perception has been formulated by Craig $(2008 ; 2009)$ who suggests that the anterior insula, by integrating interoception and the processing of emotional moments over time, creates the experience of duration (defined by successive moments in time) using information originating within the body. The insular cortex is part of the extended limbic system, and is strongly involved in subjective feeling states and interoceptive (within the body) awareness. It is specifically implicated as the basic receptive area for visceral input, that is, for physiological states of the body (Craig, 2002; Critchley, Wiens, Rotshtein, Öhman, \& Dolan, 2004; Saper, 2002). In his model Craig (2002) assumes that signals received in the dorsal posterior insula (the primary sensory area for visceral signals) are processed in a posterior-to-anterior progression and cumulates in the anterior insula, which is associated with the awareness of emotional and visceral states. Thus, the insula sequentially integrates body states and internal autonomic responses with cognitive and motivational conditions, the latter being instantiated by distributed neural processes across the brain. In line with this proposal we show that the posterior insula is a key neural substrate for the encoding of duration of multiple seconds and that, consequently, the accumulation of physiological changes in body states registered in the posterior insula may be the basis for our experience of time. It is noteworthy that in the encoding phase of the task no explicit verbal (or other motor) response related to time is required. Only in the reproduction phase a motor response has to be given, potentially requiring a stronger awareness of actual duration, which is associated with anterior insula activation. Thus, the build-up of a representation of specific duration in the posterior insula during the encoding phase (not necessarily leading to an explicit account of time) is followed by activation of the anterior insula (as well as inferior and medial frontal regions) in the reproduction phase where an explicit judgment of duration (stopping the tone) is made.

The pre-SMA and SMA have repeatedly been implicated as part of a fronto-striatal network responsible for the processing of temporal intervals (Coull, Vidal, Nazarian, \& Macar, 2004; Matell \& Meck, 2004; Pouthas, George, Poline, Pfeuty, van de Moorteele, Hugueville,

Ferrandez, Lehericy, Le Bihan, \& Renault, 2005) and also discussed as serving as a temporal accumulator (Macar, Lejeune, Bonnet, Ferrera, Pouthas, Vidal, \& Maquet, 2002). Here we also show prominent SMA activation, although, it may not to be specifically involved in the encoding of duration of several-second intervals for later retrieval. Instead, the u-shape function might be indicative of other cognitive processes supportive of the timing task. The u-shaped time activity curves presented in our study show for both the 9 and the 18-second interval a peak at approximately 10 to $12 \mathrm{~s}$ (Fig. 4). As the $3 \mathrm{~s}$ time interval would have shown its peak activity at approximately $9 \mathrm{~s}$ ( $3 \mathrm{~s}$ stimulus duration plus an additional $6 \mathrm{~s}$ delay), the average peak at 10 to $12 \mathrm{~s}$ delay in the SMA during the longer time intervals could, thus, correspond to the realization and anticipation of longer duration. This interpretation is consistent with another study, which revealed a similar rise-and-fall activity in the SMA that was reflective of learned expectations about the distribution of possible wait times (Cui, Stetson, Montague, \& Eagleman, 2009). Moreover, another study using a duration discrimination task showed that SMA activation for the second probe stimulus was detected to be more anterior and dorsal to activation of the first sample stimulus (Coull, Nazarian, \& Vidal, 2008), which is consistent with our finding of the involvement of two spatially separated regions of SMA and pre-SMA during different phases of duration reproduction. 
Similar to previous neuroimaging findings (Rubia \& Smith, 2004), the inferior frontal cortex was consistently activated during various conditions of our timing task. In particular, bilateral inferior frontal cortex activations were observed during reproduction relative to the encoding phase (Table 3). The inferior frontal cortex has repeatedly be identified as serving executive functions, i.e. the inhibitory control of premature responses in motor tasks (Aron, Fletcher, Bullmore, Sahakian, \& Robbins, 2003) as well as involved in inter-temporal decisions (Wittmann, Lovero, Lane, \& Paulus, 2010), a related role it could have had during the reproduction phase of the task when subjects had to decide on when to press the response button. In comparison, we did not find strong evidence in dorsolateral prefrontal cortex, a region of the brain that was repeatedly shown to be involved in time perception in the milliseconds to multiple seconds range in studies with patients with brain injuries (Harrington et al., 1998; Koch, Oliveri, Carlesimo, \& Caltagirone, 2002), in studies with healthy subjects using transcranial magnetic stimulation (Jones, Rosenkranz, Rothwell, \& Jahanshahi, 2004; Koch, Oliveri, Torriero, \& Caltagirone, 2003) as well as in research using neuroimaging techniques (Coull et al., 2008; Lewis \& Miall, 2003). It is possible that activation in the dorsolateral prefrontal cortex is related to general working-memory processes (not specific to timing) that could have been subtracted out in our specific fMRI contrasts. Only the contrast between the $3 \mathrm{~s}$ and the $18 \mathrm{~s}$ interval condition during the encoding phase showed a significant activation site in the right superior and middle frontal cortex for the shorter interval.

The involvement of the superior temporal cortex in our study with multiple-second intervals confers with findings of modality specific (e.g. auditory) timing processes in the sub-second and supra-second range (Bueti, van Dongen, \& Walsh, 2008b; Coull et al., 2008). Our tentative interpretation is that an accumulation of activation in temporal cortex, which depends on the nature of the stimulus (acoustic), is matched with an accumulation of activation in the dorsal posterior insula, which receives interoceptive input. This matching of the representation of external (physical, acoustic) cues with internal cues (interoception) might be the way how the brain creates the perception of the passage of time. Our hypothesis seems speculative but future research will address this issue by combining neuroimaging techniques with direct measurements of interoceptive parameters such as heart rate, breathing cycles or skin conductance levels. Moreover, studies in clinical neuropsychology with patients suffering from brain injuries to the insular cortex will reveal whether the insula is indeed involved in the experience of time.

The main finding of this study is that the BOLD fMRI results support an integrator-like neuronal function over time involved in the representation of duration in humans. The pattern of activation for the 3-s interval differed from that observed for the longer intervals. This suggests that the perception of duration for shorter durations (up to 3 seconds) might rely on different brain areas (recruiting sensori-motor systems of the brain) than the estimation of duration in the multiple-second range (Fraisse, 1984; Morillon et al., 2009; Pöppel, 1997; 2009; Wittmann et al., 2007). The separation of the shorter from the two longer time intervals is also suggested by the high correlation in subjects' behavioral performance between the 9and 18-s temporal reproduction intervals and the lack of correlation between the 3 -s and the two longer durations.

The finding that neural activity appears to accumulate in the posterior insula provides key evidence for piecing together a theory in which interoception might function as the prime source for our subjective experience of time. Our findings together with existing studies on the influence of emotions on the experience of time (Droit-Volet \& Gil 2009; Noulhiane, Mella, Samson, Ragot, \& Pouthas, 2007; Wittmann, Vollmer, Schweiger, \& Hiddemann, 2006) may lead the way for a comprehensive understanding of temporal processing in the brain. Our results concerning climbing neural activity in circumscribed regions of the brain and similar more unspecific findings of climbing activity as found in human EEG with shorter intervals are 
compatible with the pacemaker-accumulator model of time perception (Pfeuty et al. 2005). In line with this conceptualization is it is conceivable that the number and rate of body signals accumulated in the posterior insula over a given time span creates our sense of duration. Although this conclusion is speculative, we propose that the posterior insula, which processes physiological changes in body states, is strongly involved in our experience of time.

\section{Supplementary Material}

Refer to Web version on PubMed Central for supplementary material.

\section{Acknowledgments}

This work was funded by grants from the National Institute of Drug Abuse (R03DA020687-01A1 to MP and MW), by a grant from the Kavli Institute for Brain and Mind (KIBM 07-33 to MP and MW), and by the Center of Excellence in Stress and Mental Health (MP, AS). Thanks are due to Jan Churan for his invaluable help in shaping the WinVis for Matlab scripts and to Virginie van Wassenhove and Jiri Wackermann for helpful comments on an earlier version of the manuscript.

\section{References}

Aron AR, Fletcher PC, Bullmore T, Sahakian BJ, Robbins TW. Stop-signal inhibition disrupted by damage to right inferior frontal gyrus in humans. Nature Neuroscience 2003;6:115-116.

Bucholz KK, Cadoret R, Cloninger CR, Dinwiddie SH, Hesselbrock VM, Nurnberger JI Jr, Reich T, Schmidt I, Schuckit MA. A new, semi-structured psychiatric interview for use in genetic linkage studies: a report on the reliability of the SSAGA. Journal of Studies on Alcohol 1994;55:149-158. [PubMed: 8189735]

Bueti D, Bahrami B, Walsh V. The sensory and association cortex in time perception. Journal Cognitive Neuroscience 2008a;20:1054-1062.

Bueti D, van Dongen EV, Walsh V. The role of superior temporal cortex in auditory timing. PLoS One 2008b;3:e2481. [PubMed: 18575615]

Buhusi CV, Meck WH. What makes us tick? Functional and neural mechanisms of interval timing. Nature Reviews Neuroscience 2005;6:755-765.

Church, RM. Properties of the internal clock. In: Gibbon, J.; Allan, L., editors. Timing and time perception. New York: New York Academy of Sciences; 1984. p. 566-582.

Coull JT, Vidal F, Nazarian B, Macar F. Functional anatomy of the attentional modulation of time estimation. Science 2004;303:1506-1508. [PubMed: 15001776]

Coull JT, Nazarian B, Vidal F. Timing, storage, and comparison of stimulus duration engage discrete anatomical components of a perceptual timing network. Journal of Cognitive Neuroscience 2008;20:2185-2197. [PubMed: 18457512]

Cox RW. AFNI: software for analysis and visualization of functional magnetic resonance neuroimages. Computers and Biomedical Research 1996;29:162-173. [PubMed: 8812068]

Craig AD. How do you feel? Interoception: the sense of the physiological condition of the body. Nature Reviews Neuroscience 2002;3:655-666.

Craig, AD. Interoception and emotion: a neuroanatomical perspective. In: Lewis, M.; Haviland-Jones, JM.; Barrett, LF., editors. Handbook of Emotion. New York: Guilford; 2008. p. 272-288.

Craig AD. Emotional moments across time: a possible neural basis for time perception in the anterior insula. Philosophical Transactions of the Royal Society B 2009;364:1933-1942.

Critchley HD, Wiens S, Rotshtein P, Öhman A, Dolan RJ. Neural systems supporting interoceptive awareness. Nature Neuroscience 2004;7:189-195.

Cui X, Stetson C, Montague PR, Eagleman DM. Ready...go: Amplitude of the FMRI signal encodes expectation of cue arrival time. PLoS Biology 2009;7:e1000167. [PubMed: 19652698]

Droit-Volet S, Gil S. The time-emotion paradox. Philosophical Transactions of the Royal Society B 2009;364:1943-1954. 
Durstewitz D. Self-organizing neural integrator predicts interval times through climbing activity. Journal of Neuroscience 2003;23:5342-5353. [PubMed: 12832560]

Eagleman D, Pariyadath V. Is subjective duration a signature for coding efficiency? Philosophical Transactions of the Royal Society B 2009;364:1841-1852.

Eisler H, Eisler AD. Time perception: effects of sex and sound intensity on scales of subjective duration. Scandinavian Journal of Psychology 1992;33:339-358. [PubMed: 1287826]

Fraisse P. Perception and estimation of time. Annual Review of Psychology 1984;35:1-36.

Gooch CM, Wiener M, Wencil EB, Coslett HB. Interval timing disruptions in subjects with cerebellar lesions. Neuropsychologia 2010;48:1022-1031. [PubMed: 19962999]

Harrington DL, Haaland KY, Knight RT. Cortical networks underlying mechanisms of time perception. Journal of Neuroscience 1998;18:1085-1095. [PubMed: 9437028]

Hinton SC, Harrington DL, Binder JR, Durgerian S, Rao SM. Neural systems supporting timing and chronometric counting: an fMRI study. Brain Research Cognitive Brain Research 2004;21:183-192. [PubMed: 15464350]

Hinton SC, Meck WH. Frontal-striatal circuitry activated by human peak-interval timing in the supraseconds range. Brain Research Cognitive Brain Research 2004;21:171-182. [PubMed: 15464349]

Ivry RB, Spencer RM. The neural representation of time. Current Opinion in Neurobiology 2004;14:225232. [PubMed: 15082329]

Jech R, Dusek P, Wackermann JY, Vymazal J. Cumulative blood oxygenation-level-dependent signal changes support the 'time accumulator' hypothesis. Neuroreport 2005;16:1467-1471. [PubMed: 16110273]

Jones CR, Rosenkranz K, Rothwell JC, Jahanshahi M. The right dorsolateral prefrontal cortex is essential in time reproduction: an investigation with repetitive transcranial magnetic stimulation. Experimental Brain Research 2004;158:366-372.

Karmarkar UR, Buonomano DV. Timing in the absence of clocks: encoding time in neural network states. Neuron 2007;53:427-438. [PubMed: 17270738]

Koch G, Oliveri M, Carlesimo GA, Caltagirone C. Selective deficit of time perception in a patient with right prefrontal cortex lesion. Neurology 2002;26:1658-1659. [PubMed: 12451222]

Koch G, Oliveri M, Torriero S, Caltagirone C. Underestimation of time perception after repetitive transcranial magnetic stimulation. Neurology 2003;10:1844-1846. [PubMed: 12796547]

Koch G, Brusa L, Oliveri M, Stanzione P, Caltagirone C. Memory for time intervals is impaired in left hemi-Parkinson patients. Neuropsychologia 2005;43:1163-1167. [PubMed: 15817174]

Koch G, Costa A, Brusa L, Peppe A, Gatto I, Torriero S, Lo Gerfo E, Salerno S, Oliveri M, Carlesimo GA, Caltagirone C. Impaired reproduction of second but not millisecond time intervals in Parkinson's disease. Neuropsychologia 2008;46:1305-1313. [PubMed: 18215403]

Lebedev MA, O'Doherty JE, Nicolelis MAL. Decoding of temporal intervals from cortical ensemble activity. Journal of Neurophysiology 2008;99:166-186. [PubMed: 18003881]

Leon MI, Shadlen MN. Representation of time by neurons in the posterior parietal cortex of the macaque. Neuron 2003;38:317-327. [PubMed: 12718864]

Lewis PA, Miall RC. Distinct systems for automatic and cognitively controlled time measurement: evidence from neuroimaging. Current Opinion in Neurobiology 2003a;13:250-255. [PubMed: 12744981]

Lewis PA, Miall RC. Brain activation patterns during measurements of sub- and supra-second intervals. Neuropsychologia 2003b;41:1583-1592. [PubMed: 12887983]

Livesey AC, Wall MB, Smith AT. Time perception: manipulation of task difficulty dissociates clock functions from other cognitive demands. Neuropsychologia 2007;45:321-331. [PubMed: 16934301]

Macar F, Lejeune H, Bonnet M, Ferrara A, Pouthas V, Vidal F, Maquet P. Activation of the supplementary motor area and of attentional networks during temporal processing. Experimental Brain Research 2002; 142:475-485.

Matell MS, Meck WH. Cortico-striatal circuits and interval timing: coincidence detection of oscillatory processes. Brain Research Cognitive Brain Research 2004;21:139-170. [PubMed: 15464348]

Morillon B, Kell CA, Giraud AL. Three stages and four neural systems in time estimation. Journal of Neuroscience 2009;29:14803-14811. [PubMed: 19940175] 
Noulhiane M, Mella N, Samson S, Ragot R, Pouthas V. How emotional auditory stimuli modulate time perception. Emotion 2007;7:697-704. [PubMed: 18039036]

Noulhiane M, Pouthas V, Samson S. Is time reproduction sensitive to sensory modalities? European Journal of Cognitive Psychology 2009;21:18-34.

Pfeuty M, Ragot R, Pouthas V. Relationship between CNV and timing of an upcoming event. Neuroscience Letters 2005;382:106-111. [PubMed: 15911131]

Pöppel E. A hierarchical model of temporal perception. Trends of Cognitive Sciences 1997;1:56-61.

Pöppel E. Pre-semantically defined temporal windows for cognitive processing. Philosophical Transactions of the Royal Society B 2009;364:1887-1896.

Pouthas V, George N, Poline JB, Pfeuty M, van de Moorteele PF, Hugueville L, Ferrandez AM, Lehericy S, Le Bihan D, Renault B. Neural network involved in time perception: An fMRI study comparing long and short interval estimation. Human Brain Mapping 2005;25:433-441. [PubMed: 15852471]

Praamstra P, Kourtis D, Fei Kwok H, Oostenveld R. Neurophysiology of implicit timing in serial choice reaction-time performance. Journal of Neuroscience 2006;26:5448-5455. [PubMed: 16707797]

Rao SM, Mayer AR, Harrington DL. The evolution of brain activation during temporal processing. Nature Neuroscience 2001;4:317-323.

Reutimann J, Yakovlev V, Fusi S, Senn W. Climbing neuronal activity as an event-based cortical representation of time. Journal of Neuroscience 2004;24:3295-3303. [PubMed: 15056709]

Rubia K, Smith A. The neural correlates of cognitive time management: a review. Acta Neurobiologiae Experimentalis 2004;64:329-340. [PubMed: 15283476]

Saper CB. The central autonomic nervous system: conscious visceral perception and autonomic pattern generation. Annual Review of Neuroscience 2002;25:433-469.

Sawyer TF, Meyers PJ, Huser SJ. Contrasting task demands alter the perceived duration of brief time intervals. Perception \& Psychophysics 1994;56:649-657. [PubMed: 7816535]

Smith A, Taylor E, Lidzba K, Rubia K. A right hemispheric frontocerebellar network for time discrimination of several hundreds of milliseconds. Neuroimage 2003;20:344-350. [PubMed: 14527594]

Staddon JER. Interval timing: memory, not a clock. Trends in Cognitive Sciences 2005;9:312-314. [PubMed: 15953755]

Talairach, J.; Tournoux, P. Co-planar stereotaxic atlas of the human brain. Stuttgart, New York: Thieme; 1988.

Treisman M, Faulkner A, Naish PLN, Brogan D. The internal clock: evidence for a temporal oscillator underlying time perception with some estimates of its characteristic frequency. Perception 1990;19:705-743. [PubMed: 2130371]

Ulbrich P, Churan J, Fink M, Wittmann M. Temporal reproduction: further evidence for two processes. Acta Psychologica 2007;125:51-65. [PubMed: 16904621]

Vierordt, K. Der Zeitsinn nach Versuchen. Tübingen: Laupp; 1868.

Wackermann J, Ehm W. The dual klepsydra model of internal time representation and time reproduction. Journal of Theoretical Biology 2006;239:482-493. [PubMed: 16202427]

Wiener M, Turkeltaub P, Coslett HB. The image of time: a voxel-wise meta-analysis. Neuroimage 2010;49:1728-1740. [PubMed: 19800975]

Wittmann M. Time perception and temporal processing levels of the brain. Chronobiology International 1999;16:17-32. [PubMed: 10023573]

Wittmann M. The inner experience of time. Philosophical Transactions of the Royal Society B 2009;364:1955-1967.

Wittmann M, Vollmer T, Schweiger C, Hiddemann W. The relation between the experience of time and psychological distress in patients with hematological malignancies. Palliative \& Supportive Care 2006;4:357-364. [PubMed: 17133895]

Wittmann M, Carter O, Hasler F, Cahn BR, Grimberg U, Spring P, Hell D, Flohr H, Vollenweider FX. Effects of psilocybin on time perception and temporal control of behaviour in humans. Journal of Psychopharmacology 2007a;21:50-64. [PubMed: 16714323]

Wittmann M, Paulus MP. Decision making, impulsivity and time perception. Trends in Cognitive Sciences 2008;12:7-12. [PubMed: 18042423] 
Wittmann M, Lovero KL, Lane SD, Paulus M. Now or later? Striatum and insula activation to immediate versus delayed rewards. Journal of Neuroscience, Psychology, and Economics, 2010;3:15-26.

Zakay D, Block RA. Temporal cognition. Current Directions in Psychological Science 1997;6:12-16. 

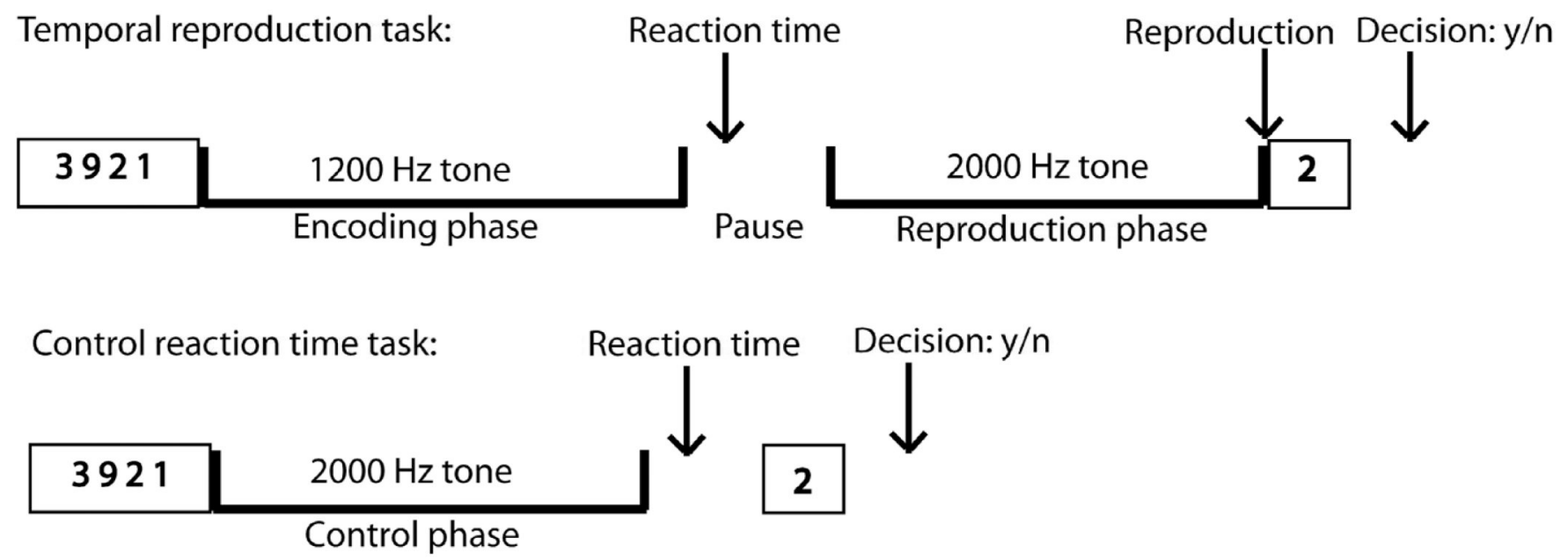

Fig. 1.

Experimental Design. Trial events in the temporal reproduction and the control reaction time task: To discourage subjects from counting (which they were instructed not to), in both the timing and the control task, a secondary memory task had to be performed. In the timing task, subjects first saw for three seconds four numbers on the screen. Then, a continuous $1.2 \mathrm{~Hz}$ tone was presented for one of three durations (3-, 9-, 18-s). After the tone had stopped subjects had to press a button as fast as possible. After a short pause a continuous $2 \mathrm{~Hz}$ tone was presented that had to be stopped by pressing a button when the subjects thought that it has lasted as long as the first stimulus. Then one single number appeared on the screen and subjects had to decide by pressing one of two buttons whether it was one of the four numbers seen at the beginning of the trial. The control reaction time task was characterized by subjects reacting as fast as possible with a button press when a $1.2 \mathrm{~Hz}$ tone stopped. 


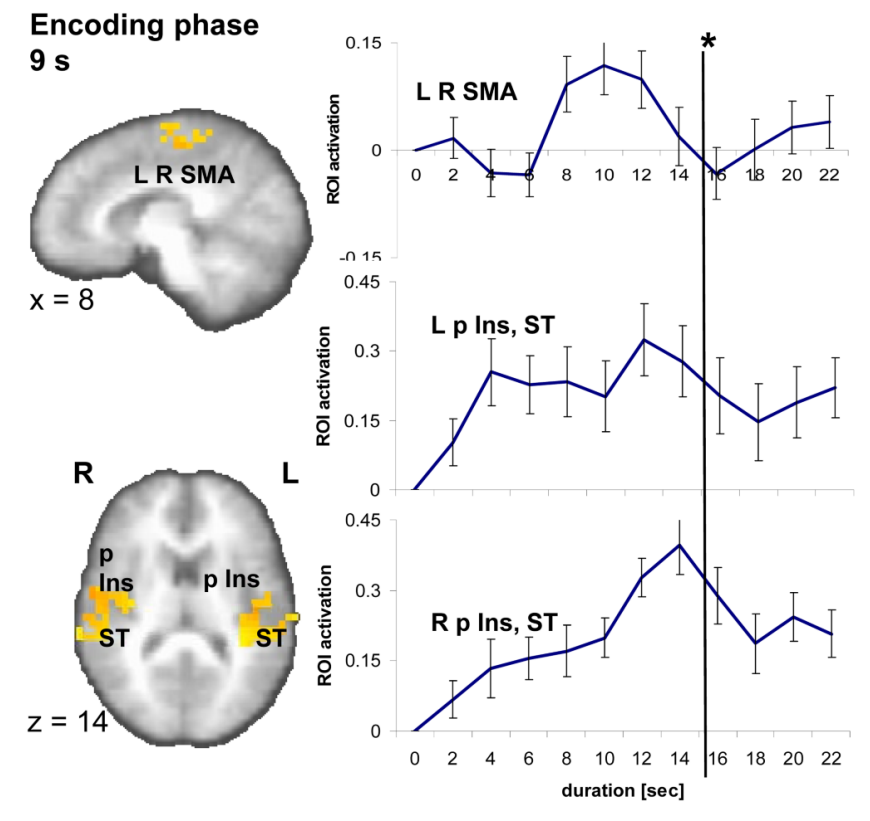

* projected peak of hemodynamic response

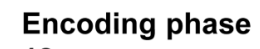

$18 \mathrm{~s}$
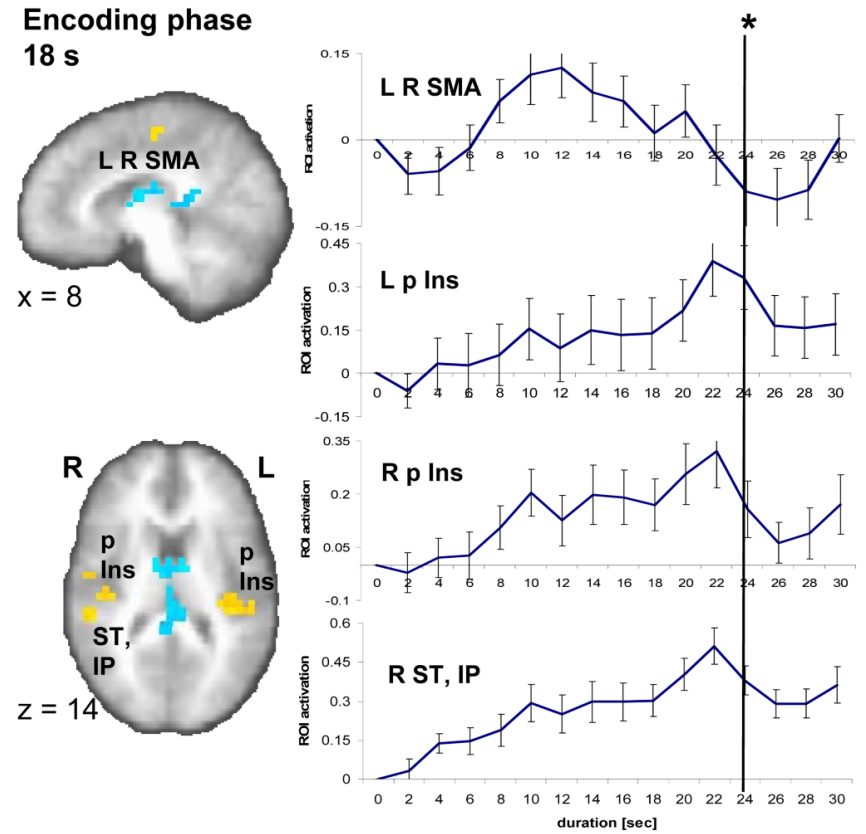

* projected peak of hemodynamic response

Fig. 2.

Brain activity during the 9-s (left) and 18-s (right) encoding phase. A sagittal $(\mathrm{x}=8)$ and an axial slice $(\mathrm{z}=14)$ show significant brain activity $(\mathrm{p}<0.01$, corrected) in three regions encompassing a bilateral medial frontal area (SMA), left and right posterior insula (p Ins) as well as superior temporal cortex (ST) as related to the encoding versus control contrast in the 9-s and 18-s conditions. Individual time activity curves (set to zero at the onset of the stimulus) show an inverted $\mathrm{u}$-shape function in the SMA and climbing brain activity that peaks at the end of the stimulus (with a delay of ca. 6 seconds reflecting the hemodynamic response function) for left (L) and right (R) p Ins, ST. 

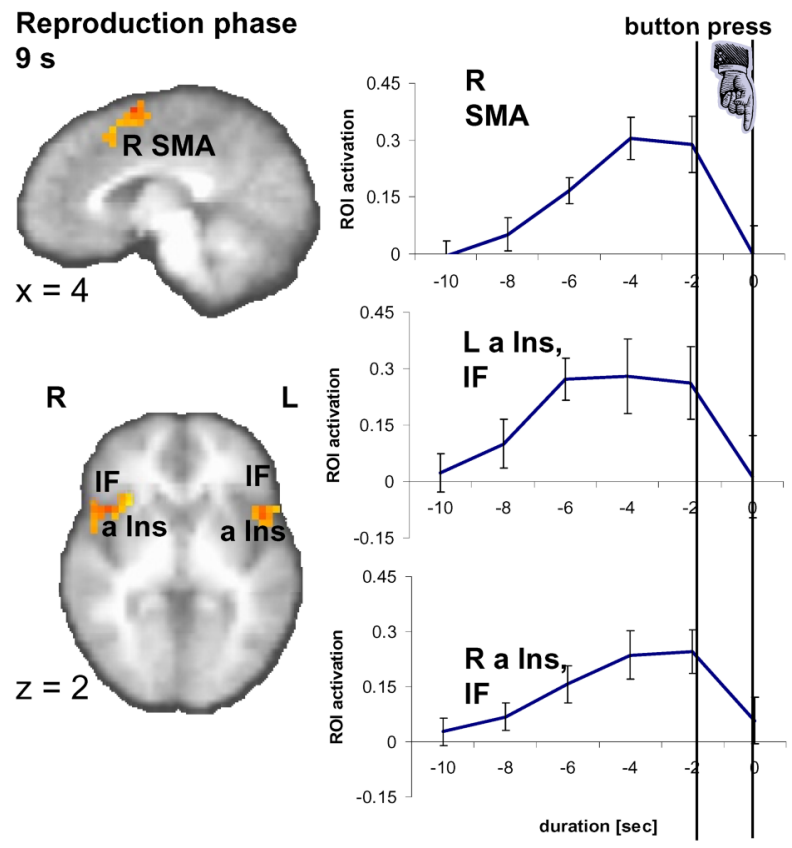

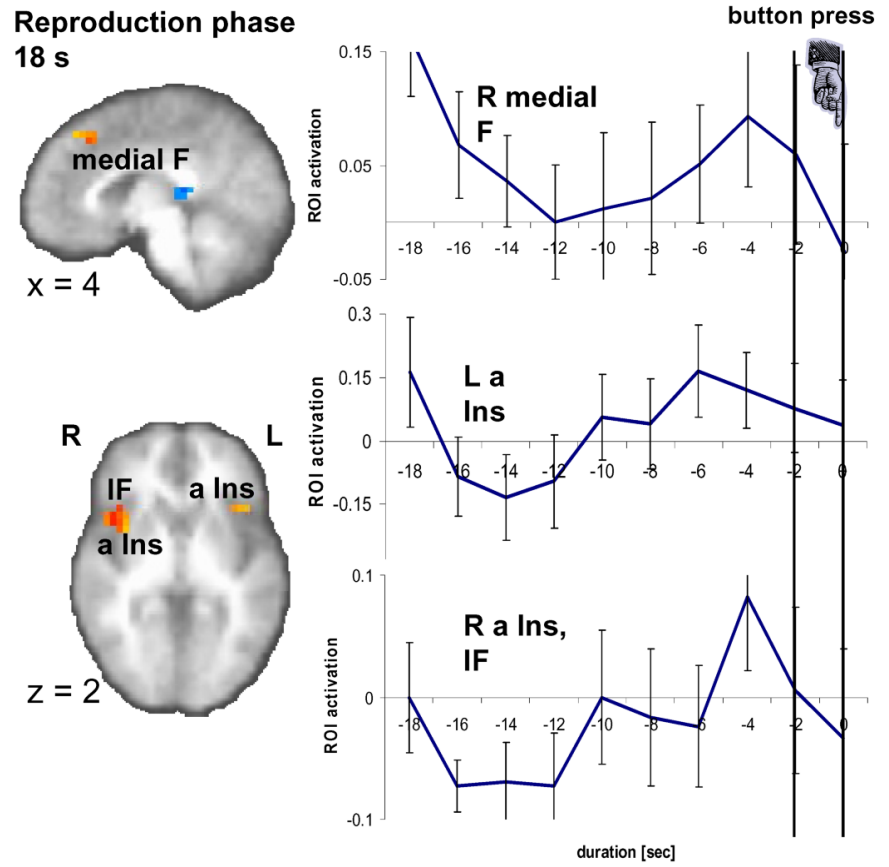

Fig. 3.

Brain activity during the 9-s and 18-s reproduction phase. A sagittal $(x=4)$ and an axial slice $(\mathrm{z}=2)$ show significant brain activity $(\mathrm{p}<0.01$, corrected) in three regions encompassing right medial frontal areas (SMA, medial F), left and right anterior insula (a Ins) as well as inferior frontal cortex (IF) as related to the reproduction versus control contrast in the 9-s and 18-s conditions. Time activity curves in the ROI as registered during the reproduction phase, namely right SMA and bilateral anterior insula (a Ins) and inferior frontal (IF) cortex, peak just before the button press. 


\section{3 seconds}
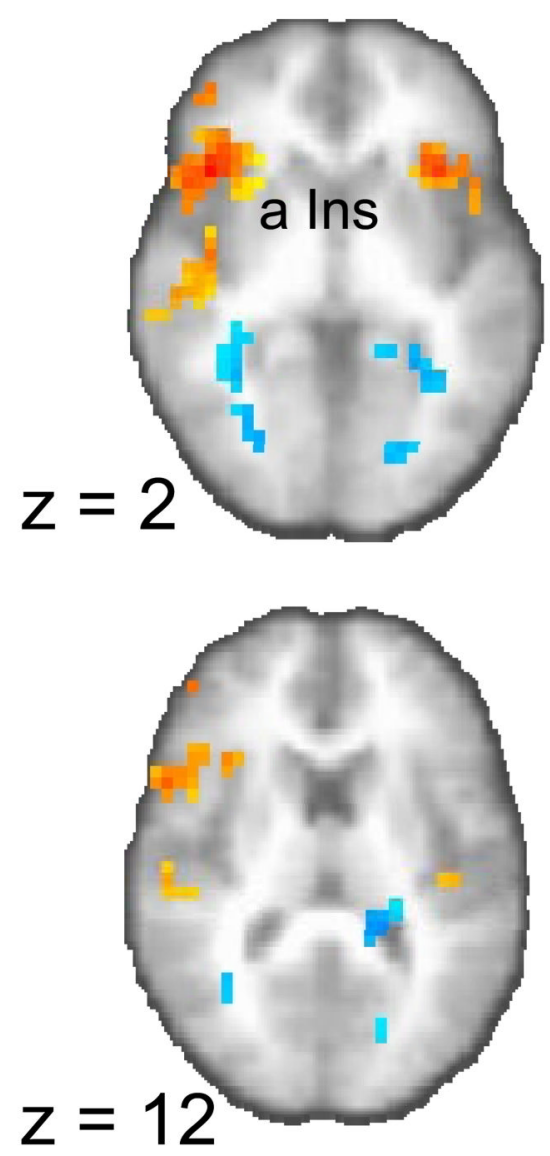

Fig. 4. p Ins).
9 seconds
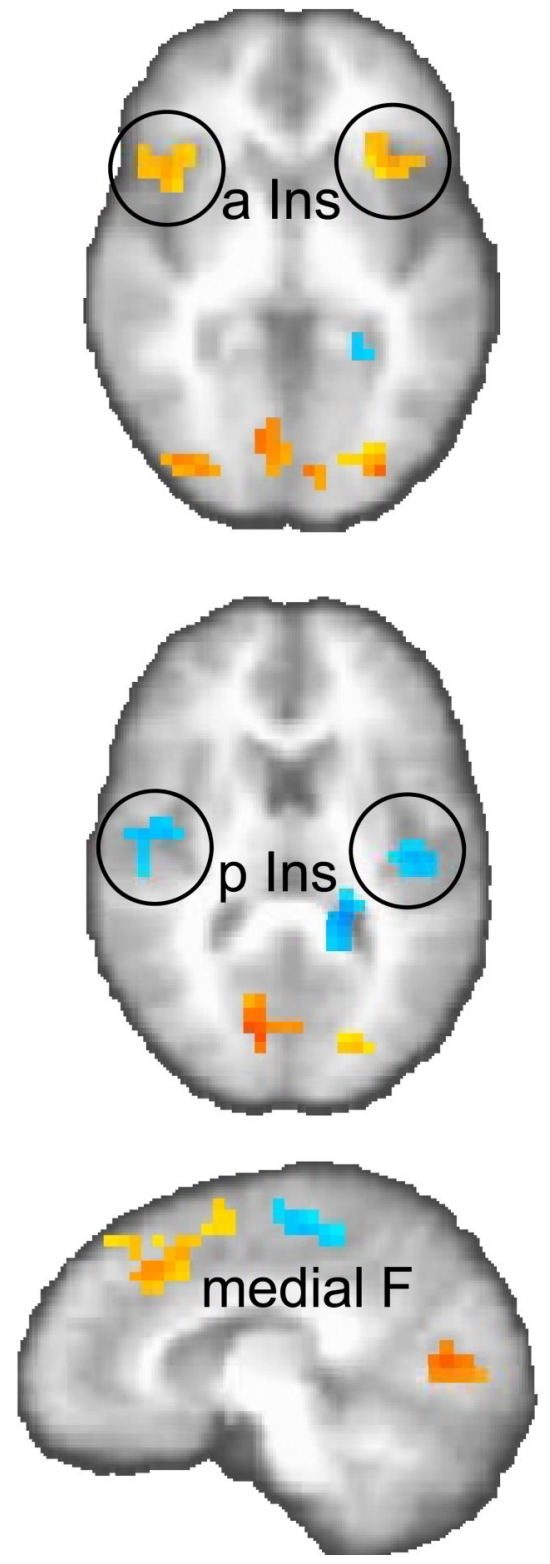

\section{8 seconds}
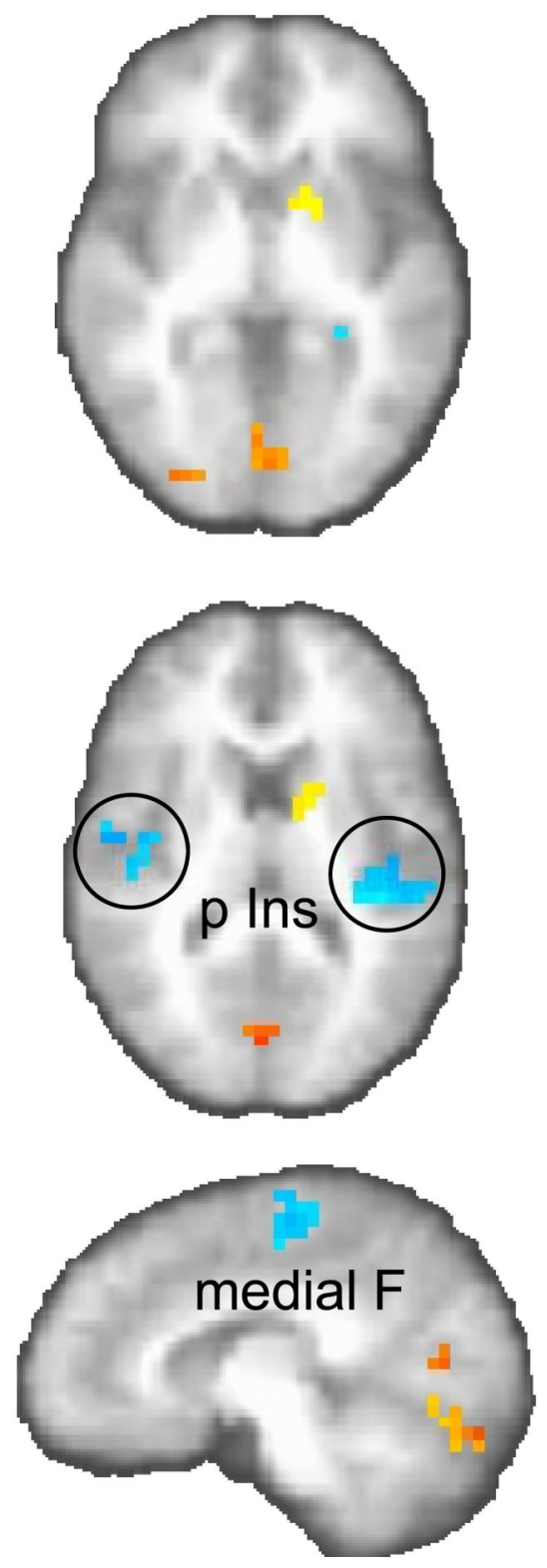

Significant brain activation for the contrast reproduction versus encoding phase $(\mathrm{p}<0.01$, corrected) on two axial $(z=2,12)$ and one sagittal plane $(x=7)$. Stronger activation in the reproduction phase is colored in yellow to red (focus point: bilateral anterior insula, a Ins), stronger activation in the encoding phase is coded in blue (focus point: bilateral posterior insula, 


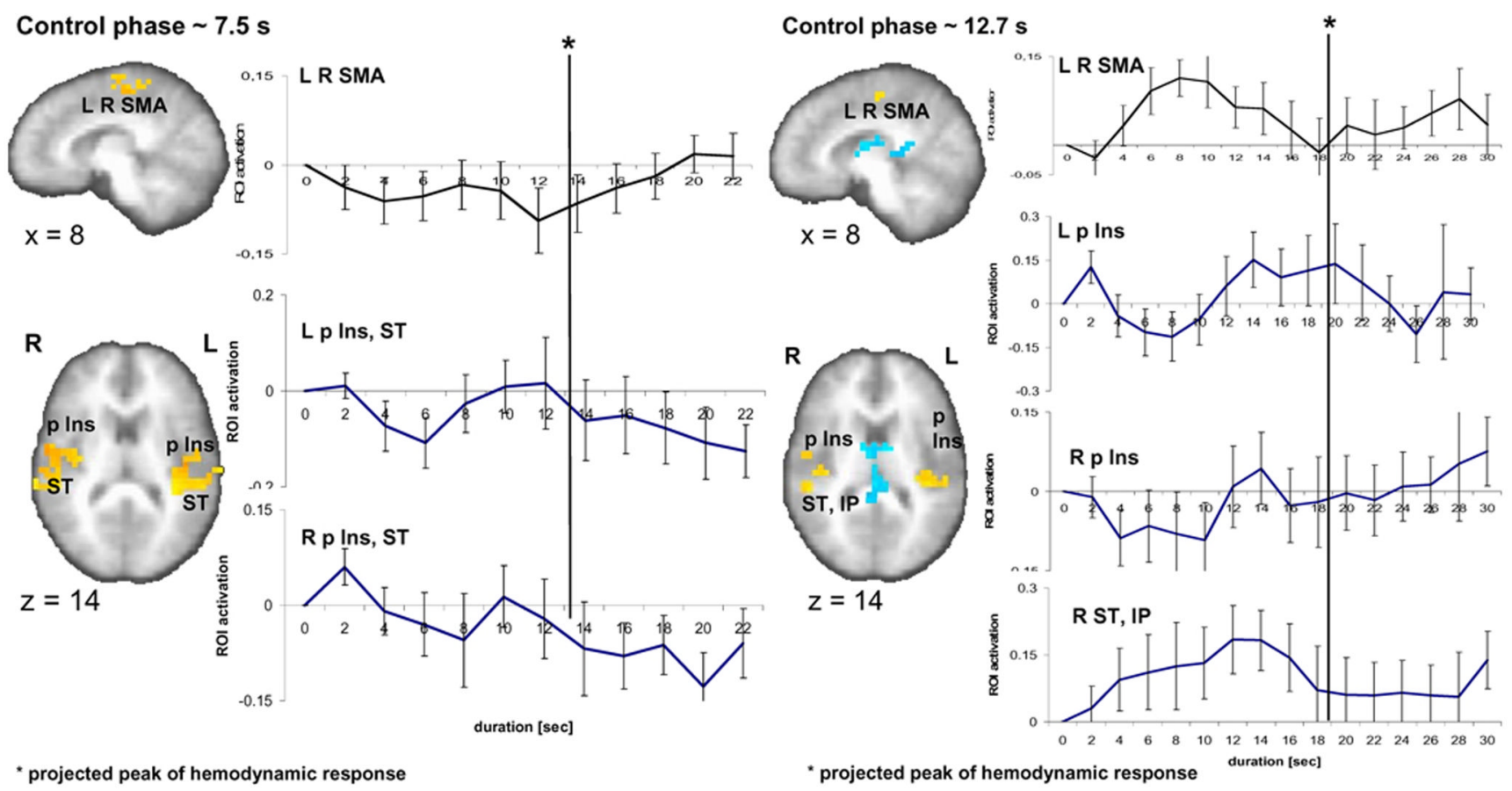

Fig. 5.

Brain activity related to the 9-s and 18-s control condition. Time activity curves registered in the ROI for the 9-s and 18-s encoding versus control conditions displayed for the control phase lasted on average $7.5 \mathrm{~s}$ and $12.7 \mathrm{~s}$, respectively. No significant slopes are detected during this control duration phase. 


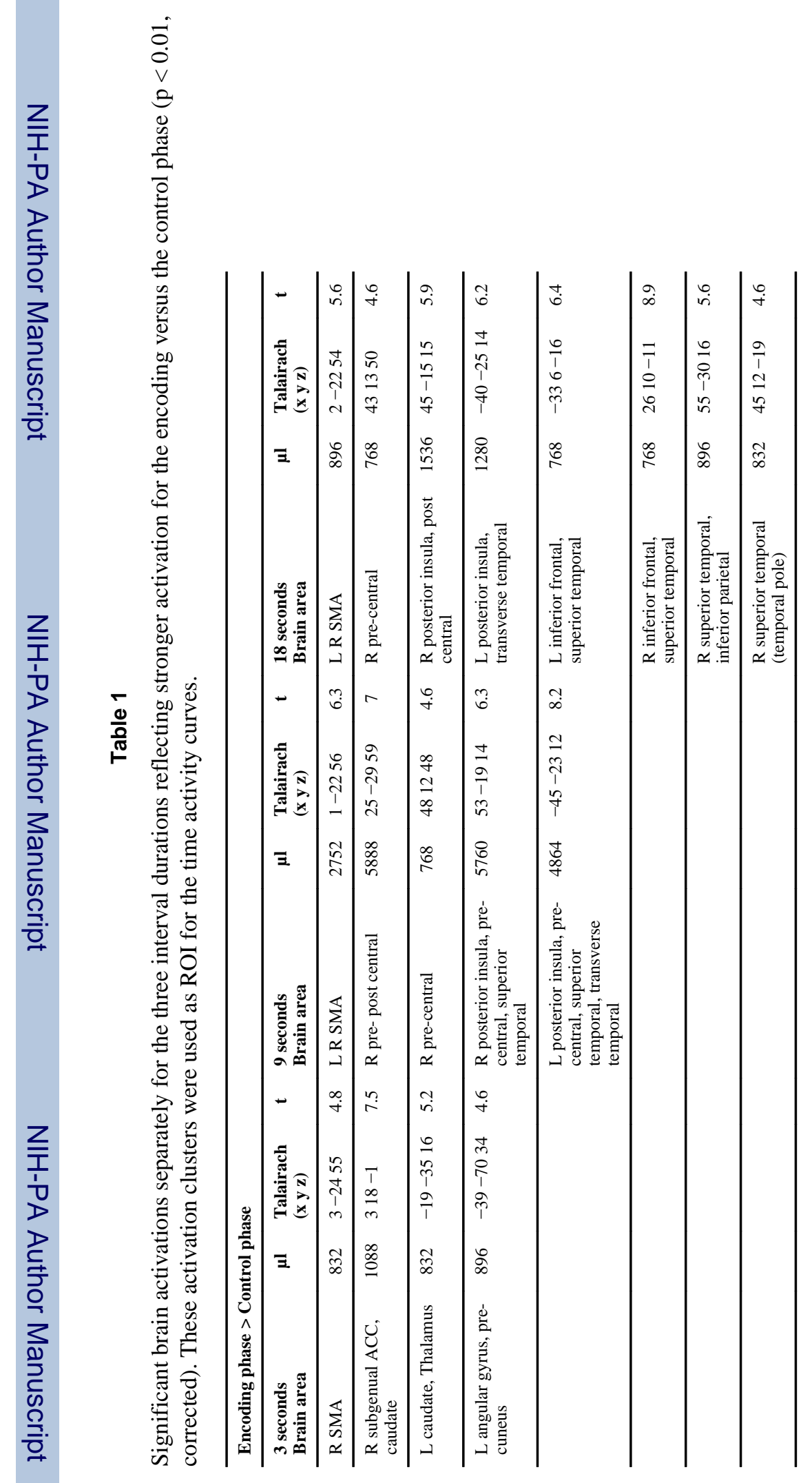




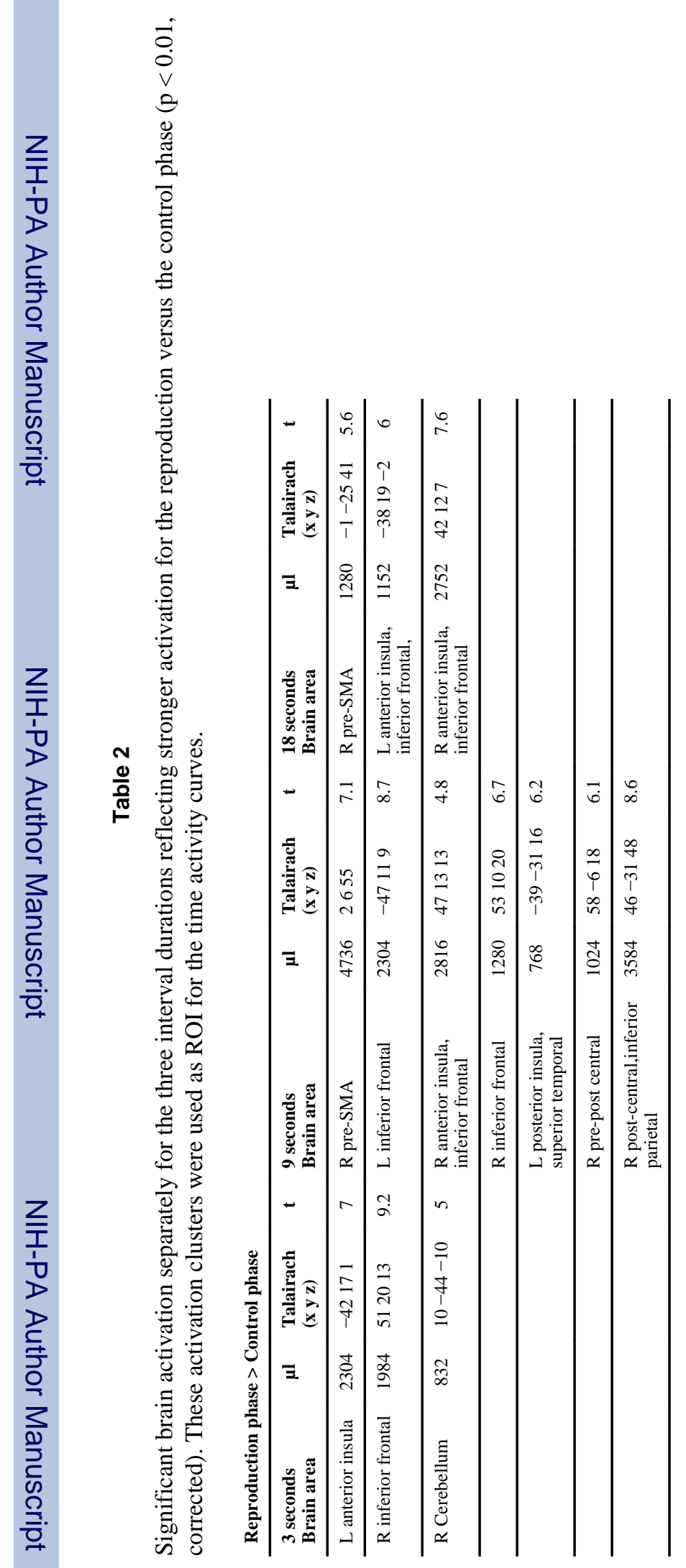


.

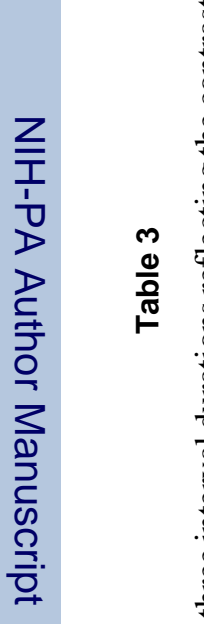

20.

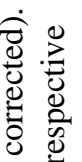

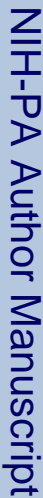

웅

萡

e.

突

:

8

记

을

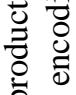

를 믈

尊

$\stackrel{0}{0}$

on

卷

逮

응

苛苟

율

壱

巳ั:

递

可苛

त्रे क्षे

.

흥

造

을

.

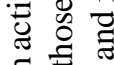

๘

흥ㅎㅇ 흉

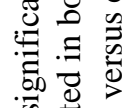

ज㻤

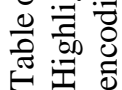

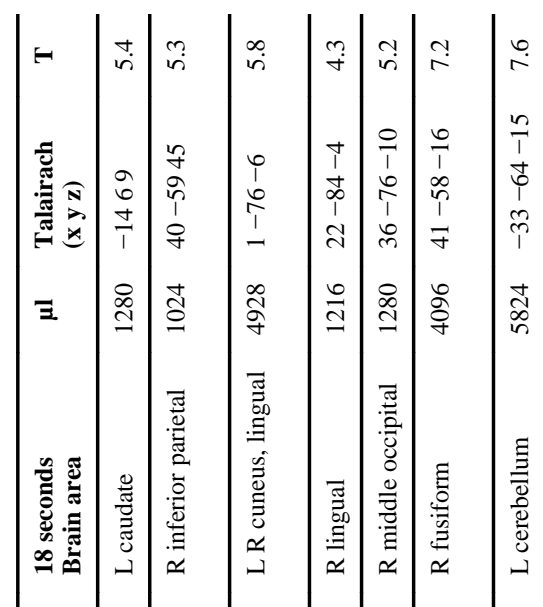

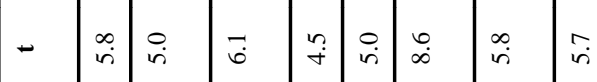

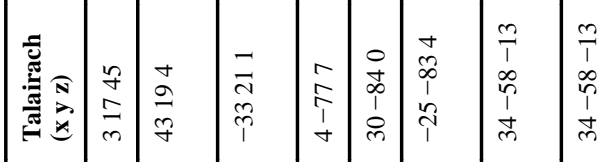

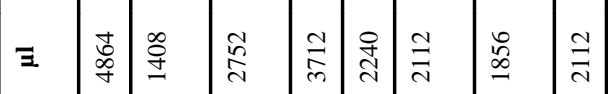

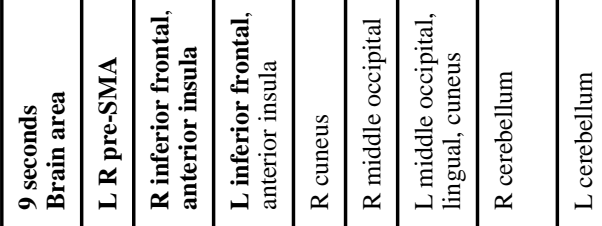

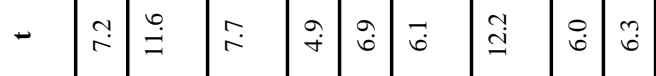

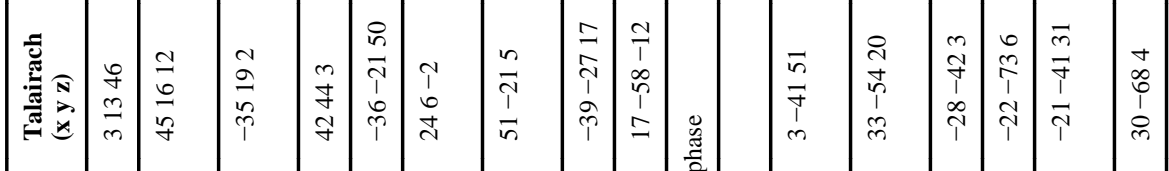

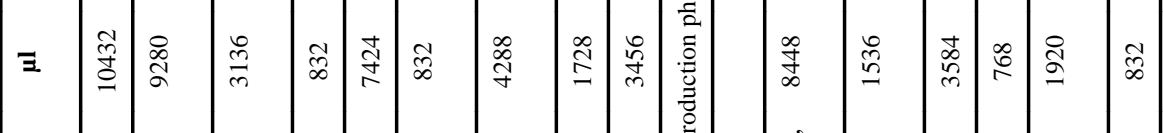

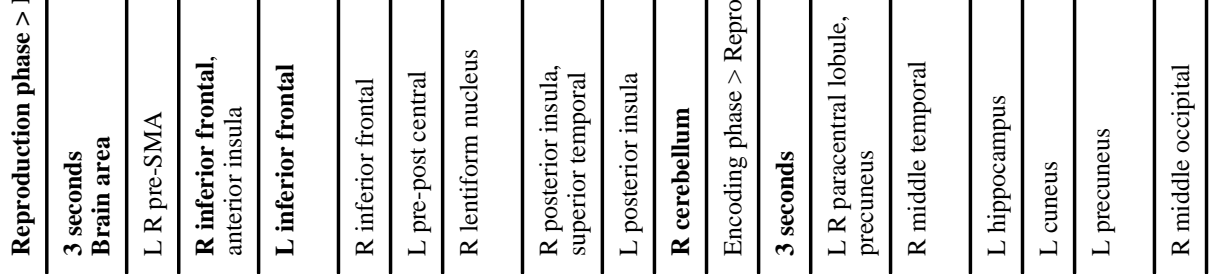


Table 4

Results of the factor analysis (Principal Component Analysis with Varimax Rotation) based on a correlation matrix encompassing the regions of interests (ROI) in the 9 second (a) and 18-second (b) encoding interval condition and the respective activations over time (for 7 and $11 \mathrm{fMRI}$ acquisition times for the respective duration of the encoding interval). Factors with Eigenvalues $>1$ were extracted.

\begin{tabular}{rlc}
\hline (a) Factor loadings for the 9-second encoding interval \\
\hline ROI & $\begin{array}{l}\text { Factor 1 } \\
\text { inverted } \\
\text { u-shape }\end{array}$ & $\begin{array}{c}\text { Factor 2 } \\
\text { climbing } \\
\text { activity }\end{array}$ \\
\hline $\begin{array}{r}\text { R Pre-post central } \\
\text { insula, pre-central, }\end{array}$ & $\mathbf{0 . 9 5 7}$ & 0.215 \\
superior temporal & 0.127 & $\mathbf{0 . 9 3 5}$ \\
R posterior insula, pre-central, & & \\
L posterior insuperior temporal & 0.185 & $\mathbf{0 . 9 2 4}$ \\
L R SMA & $\mathbf{0 . 9 1 0}$ & 0.149 \\
R pre-central & $\mathbf{0 . 8 1 8}$ & 0.098 \\
\hline
\end{tabular}

(b) Factor loadings for the 18-second encoding interval ${ }^{\S}$

\begin{tabular}{rlr}
\hline ROI & $\begin{array}{c}\text { Factor 1 } \\
\text { inverted } \\
\text { u-shape }\end{array}$ & $\begin{array}{c}\text { Factor 2 } \\
\text { climbing } \\
\text { activity }\end{array}$ \\
\hline R Posterior Insula, post-central & 0.347 & $\mathbf{0 . 9 2 0}$ \\
L posterior insula & -0.194 & $\mathbf{0 . 9 4 0}$ \\
R superior temporal, inferior & & \\
parietal & -0.047 & $\mathbf{0 . 9 8 5}$ \\
L R SMA & $\mathbf{0 . 9 3 4}$ & 0.105 \\
L inferior frontal, superior & & -0.207 \\
temporal & $\mathbf{0 . 7 2 1}$ & \\
R inferior frontal, superior & \\
temporal & 0.017 & $\mathbf{0 . 8 4 1}{ }^{*}$ \\
R pre-central & $\mathbf{0 . 9 1 7}$ & 0.140 \\
\hline * Climbing activity for this brain region is not discussed furthermore because activity does not peak at the end of the interval but continue to grow \\
after the end of the stimulus.
\end{tabular}

